\title{
Tuning of Integral Controller for Load Following of SMES and SSSC based Multi Area System under Deregulated Scenario
}

\author{
A.Suresh babu ${ }^{1}$, Ch.Saibabu ${ }^{2}$, S.Sivanagaraju ${ }^{3}$ \\ ${ }^{1}$ (Department of EEE, SSN Engineering College, Andhra Pradesh, India) \\ ${ }^{2,3}$ (Department of EEE, J.N.T University, Kakinada, Andhra Pradesh, India)
}

\begin{abstract}
This paper deals with the application of various evolutionary optimization techniques for optimizing the gain of integral controller in a SMES and SSSC based load following hydrothermal system under deregulated scenario. The various techniques which have been used are Simulated Annealing (SA), Genetic Algorithm (GA), Particle Swarm Optimization (PSO). A two area load following based hydrothermal system under deregulated scenario is considered to exemplify the optimum parameter search. The integral of square of error performance index is considered in the search of optimal Automatic Generation Control (AGC) parameters. The results presented in this paper demonstrate the superior working of various techniques over one another in the tuning of AGC parameters.
\end{abstract}

Keywords: Simulated Annealing, genetic algorithm, particle swarm optimization, hydrothermal system

\section{INTRODUCTION}

Large scale power systems are normally composed of control areas or regions representing coherent groups of generators. In a practically interconnected power system, the generation normally comprises of a mix of thermal, hydro, nuclear and gas power generation. However, owing to their high efficiency, nuclear plants are usually kept at base load close to their maximum output with no participation in the system AGC. Gas power generation is ideal for meeting the varying load demand. Gas plants are used to meet peak demands only. Thus the natural choice for AGC falls on either thermal or hydro units. Literature survey shows that most of earlier works in the area of AGC pertain to interconnected thermal systems and relatively lesser attention has been devoted to the AGC of interconnected hydro-thermal system involving thermal and hydro subsystem of widely different characteristics. Concordia and Kirchmayer [1] have studied the AGC of a hydro-thermal system considering non-reheat type thermal system neglecting generation rate constraints. Kothari, Kaul, Nanda [2] have investigated the AGC problem of a hydro-thermal system provided with integral type supplementary controllers. The model uses continuous mode strategy, where both system and controllers are assumed to work in the continuous mode.

On the other hand, the concept of utilizing power electronic devices for power system control has been widely accepted in the form of Flexible AC Transmission Systems (FACTS) which provide more flexibility in power system operation and control [3].An attempt was made to use battery energy storage system(BES) to improve the LFC[4]. The problems like low discharge rate, increased time required for power flow reversal and maintenance requirements have led to the evaluation of superconducting magnetic energy storage (SMES) for their applications as load frequency stabilizers[5-7]. Static synchronous series compensator (SSSC) in one of the important member of FACTS family which can be installed in series with the transmission lines [8]. With capability to change its reactance characteristic from capacitive to inductive, the SSSC is very effective in controlling power flow and application of SSSC for frequency regulation by placing it series with tie-line between interconnected two area power systems with thermal units is proposed [9-10]. The reported works [11-13] further shows that, with the use of SMES in both the areas, frequency deviations in each area are effectively suppressed. In view of this the main objective of the present work is:

To compare the improvement of dynamic performance of the system by optimizing the gain of integral controller in a SMES and SSSC based load following hydrothermal system under deregulated scenario using various optimization techniques namely SA, GA and PSO. Simulation results show that PSO technique can give good improvement in dynamic performance of two area hydrothermal system under various conditions.

\section{DYNAMIC MATHEMATICAL MODEL}

Electric power systems are complex, nonlinear dynamic system. The Load Frequency controller controls the control valves associated with High Pressure (HP) turbine at very small load variations. The system under investigation has tandem-compound single reheat type thermal system. Each element (Governor, turbine and power system) of the system is represented by first order transfer function at small load variations in according to the IEEE committee report [18]. Fig. 1 shows the transfer function block diagram of a two area interconnected network under deregulated scenario . The parameters of two area model are defined in Appendix. 


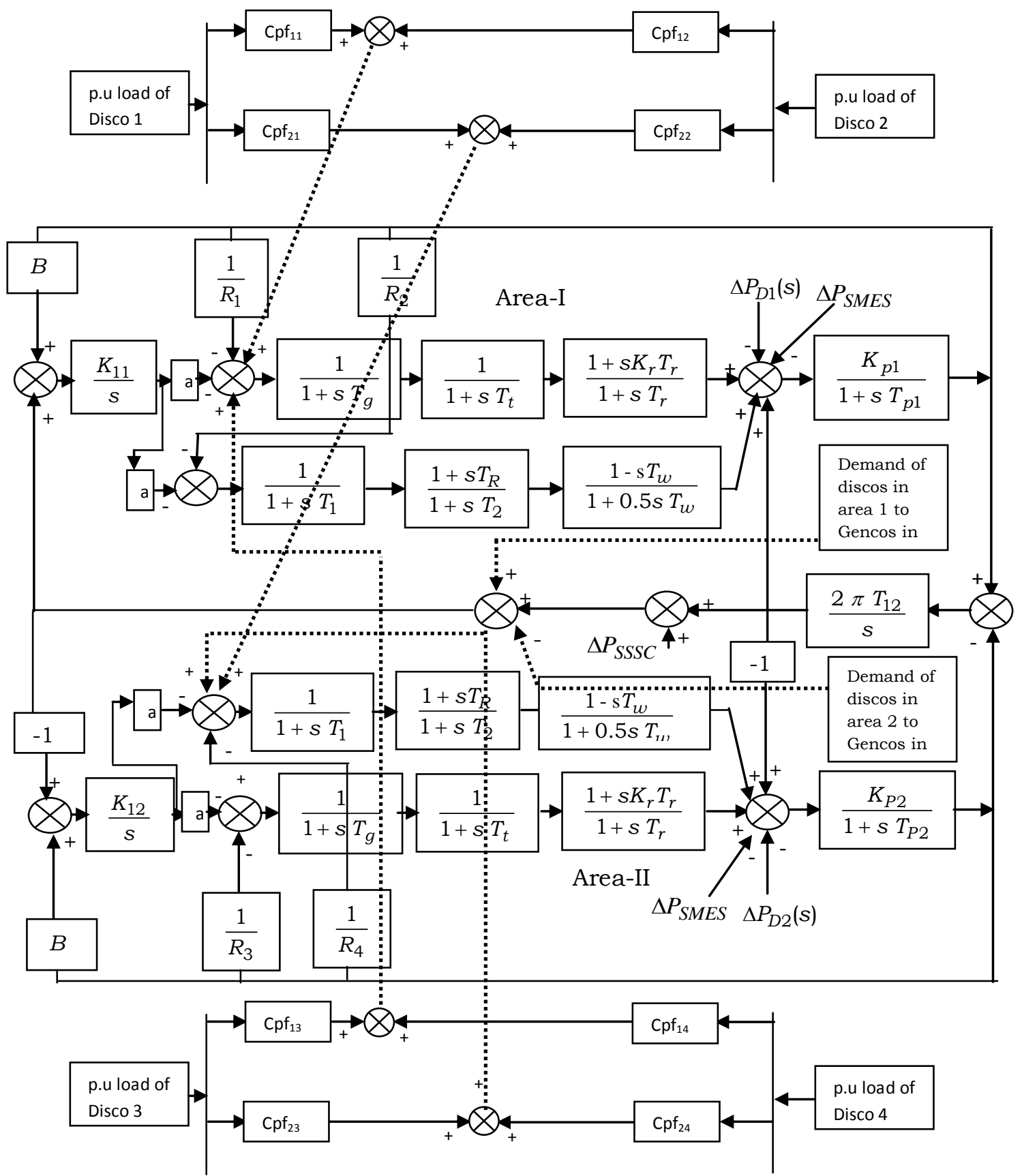

Fig. 1. Two Area load following Hydrothermal system with SSSC and SMES

\section{DESIGN OF SMES}

Either frequency deviation or Area Control Error (ACE) can be used as the control signal to the SMES unit. In this work the frequency deviation of area 1 is employed as input to the SMES device. It can be seen from Figure 2 that the structure of SMES consists of gain block $K_{S M E S}$, time constant $T_{S M E S}$ and two stage phase compensation blocks having time constants $T_{1}, T_{2}, T_{3}, T_{4}$ respectively. A performance index considered in this work to compare the performance of proposed method is given by $J=\int_{0}^{t}\left(\alpha \times \Delta f_{1}^{2}+\beta \times \Delta f_{2}^{2}+\Delta P_{\text {tie } 12}^{2}\right)$

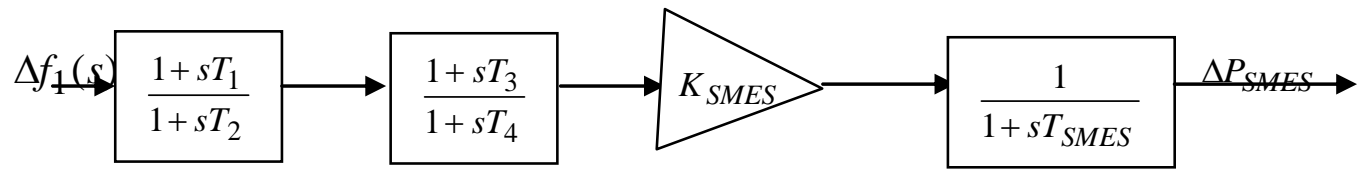

Fig. 2. Schematic diagram of SMES applied to system 


\section{DESIGN OF SSSC}

The block diagram of SSSC to be incorporated in the two area system in order to reduce the frequency deviations is provided in Figure 3 shown below. The frequency deviation of area 1 can be seen as input to the SSSC device. It can be seen from Fig 3 that the structure of SSSC consists of gain block $K_{\text {SSSC }}$, time constant $T_{S S S C}$ and two stage phase compensation blocks having time constants $T_{1}, T_{2}, T_{3}, T_{4}$ respectively.

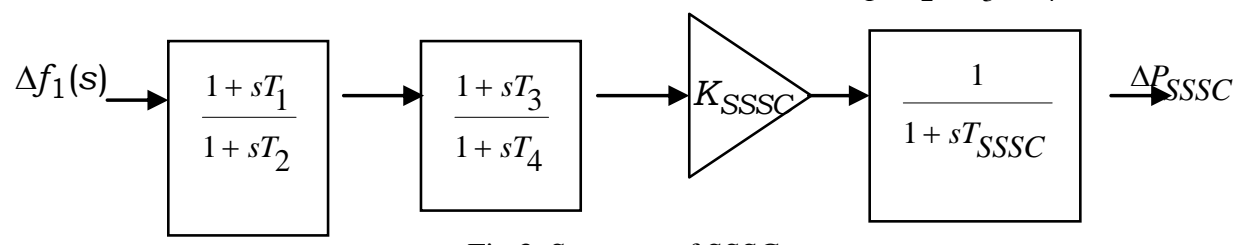

Fig 3: Structure of SSSC

\section{EVOLUTIONARY OPTIMIZATION TECHNIQUES EMPLOYED}

Brief descriptions of the optimization techniques employed are as given:

\section{a). Simulated Annealing Method (SA)[21-24]}

Simulated annealing is an effective and commonly optimization algorithm used to solve non linear optimization problems. Simulated annealing (SA) is a Monte Carlo approach for minimizing multivariate functions. SA was introduced in 1983 based on ideas formulated in the early 1950s. This method simulates the annealing process in which a substance is heated above its melting temperature and then gradually cooled to produce the crystalline lattice, which minimizes its energy probability distribution. This crystalline lattice, composed of millions of atoms perfectly aligned, is a beautiful example of nature finding an optimal structure. However, quickly cooling or quenching the liquid retards the crystal formation, and the substance becomes an amorphous mass with a higher than optimum energy state. The key to crystal formation is carefully controlling the rate of change of temperature. The algorithmic analog to this process begins with a random guess of the cost function variable values. Heating means randomly modifying the variable values. Higher heat implies greater random fluctuations. The cost function returns the output, $\mathrm{f}$, associated with a set of variables. If the output decreases, then the new variable set replaces the old variable set. If the output increases, then the output is accepted provided that:

$$
r \leq e^{\left[f\left(p_{\text {old }}\right)-f\left(P_{\text {new }}\right)\right] / T}
$$

Where ' $r$ ' is uniform random number and ' $T$ ' is variable analogous to temperature. Otherwise, the new variable set is rejected. Thus, even if a variable set leads to a worse cost, it can be accepted with a certain probability. The new variable set is found by taking a random step from the old variable Set as (2).

$$
P^{\text {new }}=d P^{\text {old }}
$$

The variable $\mathrm{d}$ is either uniformly or normally distributed about $P^{\text {old }}$. This control variable sets the step size so that, at the beginning of the process, the algorithm is forced to make large changes in variable values. At times the changes move the algorithm away from the optimum, which forces the algorithm to explore new regions of variable space. After a certain number of iterations, the new variable sets no longer lead to lower costs. At this point the value of $T$ and d decrease by a certain percent and the algorithm repeats. The algorithm stops when $T=0$.The decrease in $T$ is known as the cooling schedule. Many different cooling schedules are possible. If the initial temperature is $T_{0}$ and the ending temperature is $T_{N}$, then the temperature at step $n$ is given by (3).

$T_{n}=f\left(T_{0}, T_{n}, N, n\right)$

Where, $f$ decreases with time. Some potential cooling schedules are as follows:

- Linearly decreasing: $T_{n}=T_{0}-n\left(T_{0}-T_{n}\right) / N$

- Geometrically decreasing: $T_{n}=0.99 T_{n-1}$

- Hayjek optimal: $T_{n}=c / \log (1+n)$

Where ' $c$ ' is the smallest variation required to get out of any local minimum. Many other variations are possible. The temperature is usually lowered slowly so that the algorithm has a chance to find the correct valley before trying to get to the lowest point in the valley.

\section{b). Genetic Algorithm (GA) [25-27]}

Genetic algorithm is a kind of the probabilistic heuristic search algorithm analogous to mechanics of natural selection and survival of the fittest in biology. Steps of GA as implemented for optimization are: 
- Initialization of binary chromosome strings of np population, each consisting of the gains.

- Decoding of strings and evaluation of figure of demerit of each string.

- Selection of elite strings in order of increasing figure of demerit from minimum value.

- Copying of the elite strings over the non-selected strings.

- Crossover and mutation to generate off springs.

- Genetic cycle updating and stopping criteria.

Algorithm of GA:

Step 1) Start: Create random population of $n$ chromosomes

Step 2) Fitness: Evaluate fitness $\mathrm{f}(\mathrm{x})$ of each chromos in the population

Step 3) New population:

a. Selection: Based on $\mathrm{f}(\mathrm{x})$

b. Recombination: Cross-over chromosomes

c. Mutation: Mutate chromosomes

d. Acceptation: reject or accept new one

Step 4) Replace: old with new population and the new generation

Step 5) Test : Test for problem criterion

Step 6) Loop : Continue step 2-5 until criterion is satisfied

\section{c). Particle Swam Optimization (PSO) [28-31]}

PSO was formulated by Edward and Kennedy in 1995. The thought process behind the algorithm was inspired by the social behavior of animals, such as bird flocking or fish schooling. PSO is similar to the continuous GA in that it begins with a random population matrix. Unlike the GA, PSO has no evolution operators such as crossover and mutation. The rows in the matrix are called particles (same as the GA chromosome). They contain the variable values and are not binary encoded. Each particle moves about the cost surface with a velocity. The particles update their velocities and positions based on the local and global best solutions as shown in (4) and (5) (Randy and Sue, 2004):

$$
\begin{aligned}
& V_{m, n}{ }^{\text {new }}=w \times V_{m, n}^{\text {old }}+\Gamma_{1} \times r_{1} \times\left(P_{m, n}^{\text {local best }}-P_{m, n}^{\text {old }}\right)+\Gamma_{2} \times r_{2} \times\left(P_{m, n}{ }^{\text {global best }}-P_{m, n}^{\text {old }}\right) \\
& P_{m, n}{ }^{\text {new }}=P_{m, n}{ }^{\text {old }}+\Gamma V_{m, n} \text { new }
\end{aligned}
$$

Where:

$V_{m, n}=$ particle velocity

$P_{m, n}=$ particle variables

$\mathrm{W}=$ inertia weight

$\mathrm{r}_{1}, \mathrm{r}_{2}=$ independent uniform random numbers

$\Gamma_{1}=\Gamma_{2}=$ learning factors

$\Delta P_{m, n}{ }^{\text {local best }}=$ best local solution

$\Delta P_{m, n}{ }^{\text {global best }}=$ best global solution

The PSO algorithm updates the velocity vector for each particle then adds that velocity to the particle position or values. Velocity updates are influenced by both the best global solution associated with the lowest cost ever found by a particle and the best local solution associated with the lowest cost in the present population. If the best local solution has a cost less than the cost of the current global solution, then the best local solution replaces the best global solution. The particle velocity is reminiscent of local minimizes that use derivative information, because velocity is the derivative of position. The advantages of PSO are that it is easy to implement and there are few parameters to adjust.

Algorithm of PSO:

Step 1). Initialize an array of particles with random positions and their associated velocities to satisfy the inequality constraints.

Step 2). Check for the satisfaction of the equality constraints and modify the solution if required.

Step 3). Evaluate the fitness function of each particle.

Step 4). Compare the current value of the fitness function with the particles previous best value (pbest). If the current fitness value is less, then assign the current fitness value to pbest and assign the current coordinates (positions) to pbestx.

Step 5). Determine the current global minimum fitness value among the current positions. 
Step 6). Compare the current global minimum with the previous global minimum ( $g$ best). If the current global minimum is better than gbest, then assign the current global minimum to gbest and assign the current coordinates (positions) to gbestx.

Step 7). Change the velocities.

Step 8). Move each particle to the new position and return to step 2.

Step 9). Repeat step 2-8 until a stop criterion is satisfied or the maximum number of iterations is reached.

\section{RESUlTS AND DiCUSSIONS}

Simulation studies are performed to investigate the performance of the two-area hydrothermal system under deregulated Environment. Here in the two-area hydrothermal system three Gencos and two Discos are considered in each area. It is assumed in this work that one Genco in each area is under AGC only and the remaining Gencos participate in the bilateral contracts. It is assumed that there is $0.2 \%$ step load disturbance of each Disco, as a result of which the total step load disturbance in each area and accounts to $0.4 \%$ and each Genco participates in AGC as defined by following area participation factors (apfs): $a p f_{1}=0.25, a p f_{2}=0.25$, $a p f_{3}=0.5$, apf $_{4}=0.25, \operatorname{apf}_{5}=0.25, \operatorname{apf}_{6}=0.5$ and the Discos contract with the Gencos as per the following Disco Participation Matrix

$$
\mathrm{DPM}=\left[\begin{array}{cccc}
0.25 & 0.3 & 0.1 & 0.3 \\
0.25 & 0.1 & 0.4 & 0.4 \\
0 & 0 & 0 & 0 \\
0.25 & 0.4 & 0.3 & 0.1 \\
0.25 & 0.2 & 0.2 & 0.2 \\
0 & 0 & 0 & 0
\end{array}\right]
$$

Table 1shows the comparison of performance of various optimization techniques proposed in terms of their peak time, overshoot and settling time. It can be observed that the particle swarm optimization technique gives better performance than the other techniques. Table 2 shows the performance index values of the system with these three techniques. It can also be observed from the table that the system designed with particle swarm optimization gives less performance index which indicates the superiority of the technique

Table 1: Comparison of performance of Optimization techniques

\begin{tabular}{|c|c|c|c|c|c|c|}
\hline S.no & $\begin{array}{l}\text { Optimization } \\
\text { Technique }\end{array}$ & $\begin{array}{l}\text { Integral Gain } \\
\text { values }\end{array}$ & $\begin{array}{c}\text { Area } \\
\text { Considered }\end{array}$ & $\begin{array}{l}\text { Peak } \\
\text { time } \\
(\mathrm{sec})\end{array}$ & $\begin{array}{l}\text { Overshoot } \\
(\mathrm{Hz})\end{array}$ & $\begin{array}{c}\text { Settling } \\
\text { Time } \\
\text { (sec) }\end{array}$ \\
\hline \multirow[t]{2}{*}{1} & \multirow{2}{*}{$\begin{array}{l}\text { Simulated } \\
\text { Annealing }\end{array}$} & $k_{i 1}=1.35$ & Thermal area & 1.805 & 0.003572 & 4.735 \\
\hline & & $k_{i 2}=0.267$ & Hydro area & 0.785 & 0.005707 & 3.625 \\
\hline \multirow[t]{2}{*}{2} & \multirow{2}{*}{$\begin{array}{c}\text { Genetic } \\
\text { Algorithm }\end{array}$} & $k_{i 1}=0.2307$ & Thermal area & 1.765 & 0.00352 & 4.345 \\
\hline & & $k_{i 2}=0.7918$ & Hydro area & 0.785 & 0.005701 & 3.475 \\
\hline \multirow[t]{2}{*}{3} & \multirow{2}{*}{$\begin{array}{c}\text { Particle Swarm } \\
\text { Optimization }\end{array}$} & $k_{i 1}=0.3578$ & Thermal area & 1.6 & 0.003213 & 4.06 \\
\hline & & $k_{i 2}=0.9338$ & Hydro area & 0.775 & 0.005660 & 3.135 \\
\hline
\end{tabular}

Table 2: Comparison of performance index for various optimization techniques

\begin{tabular}{|c|c|c|}
\hline S.no & Optimization technique & Performance index \\
\hline 1 & Simulated Annealing & $1.033 \times 10^{-5}$ \\
\hline 2 & Genetic Algorithm & $8.10 \times 10^{-6}$ \\
\hline 3 & Particle Swarm Optimization & $7.19 \times 10^{-6}$ \\
\hline
\end{tabular}

Fig. 4 shows the comparison between the frequency deviations and tie line power error deviations for all the three optimization techniques. Fig 5 and 6 shows the generation of gencos of both areas. Fig. 7 shows the comparison of frequency deviations and tie line power error deviations during the contract violation. Fig. 8 and 9 depict the various generation of gencos during contract violation. The comparison of all the systems in terms of performance index has been carried out in Fig.10 and 11. It can be observed from the figures that the system 
designed with the help of PSO technique less performance index than the other system which indicates the superior working of the technique.
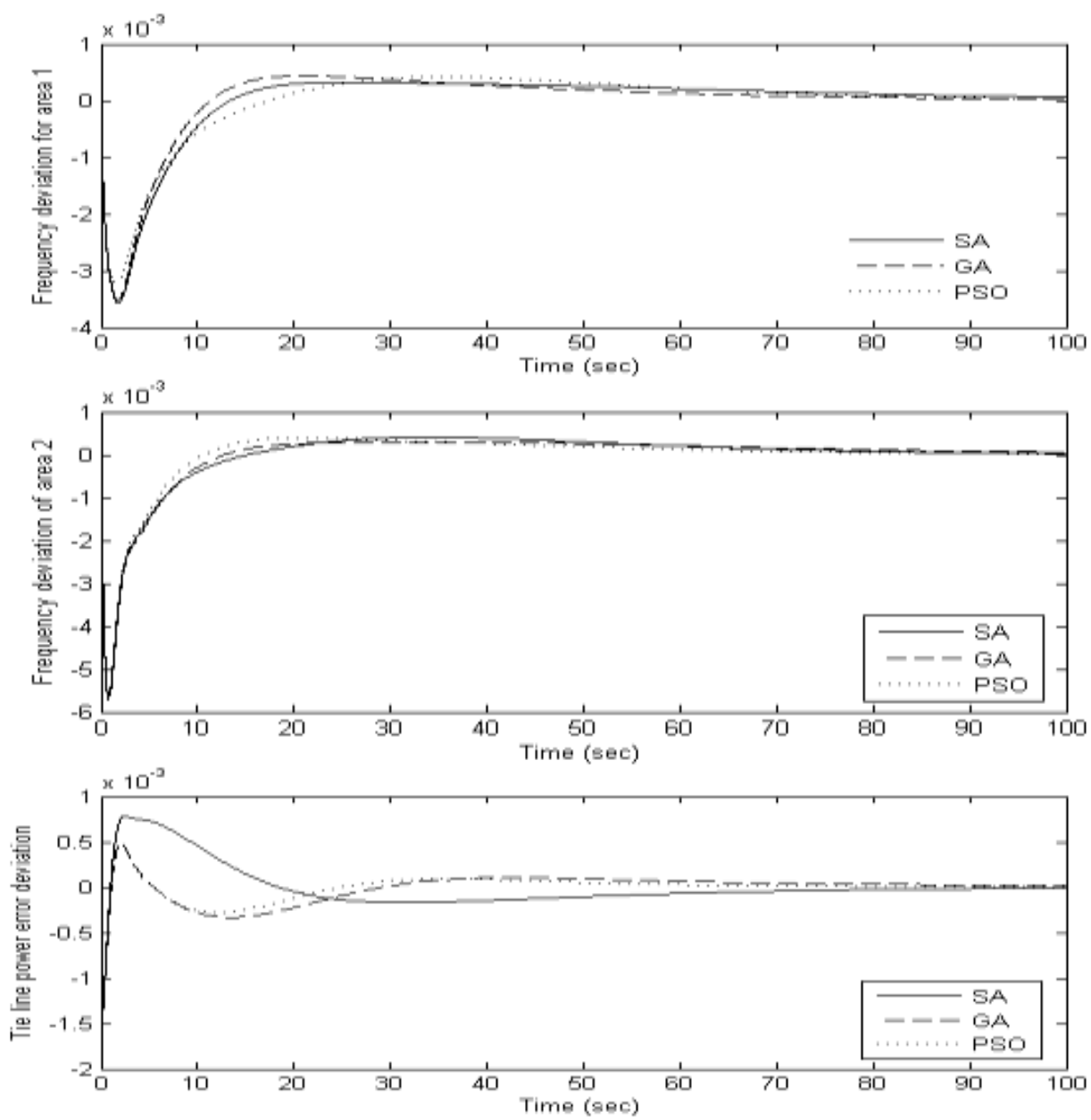

Fig 4: Comparison of Frequency deviations and tie line power error deviations
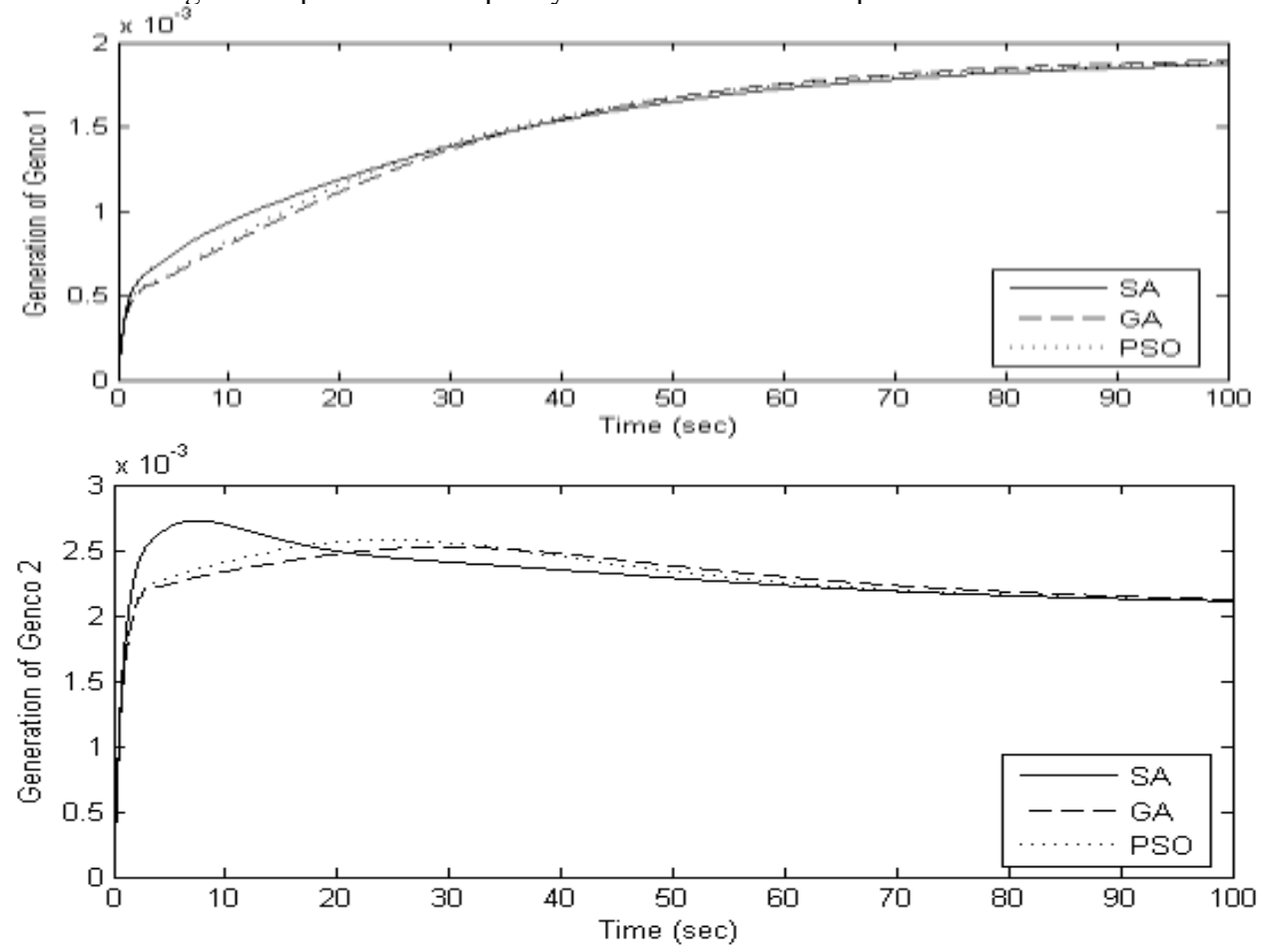


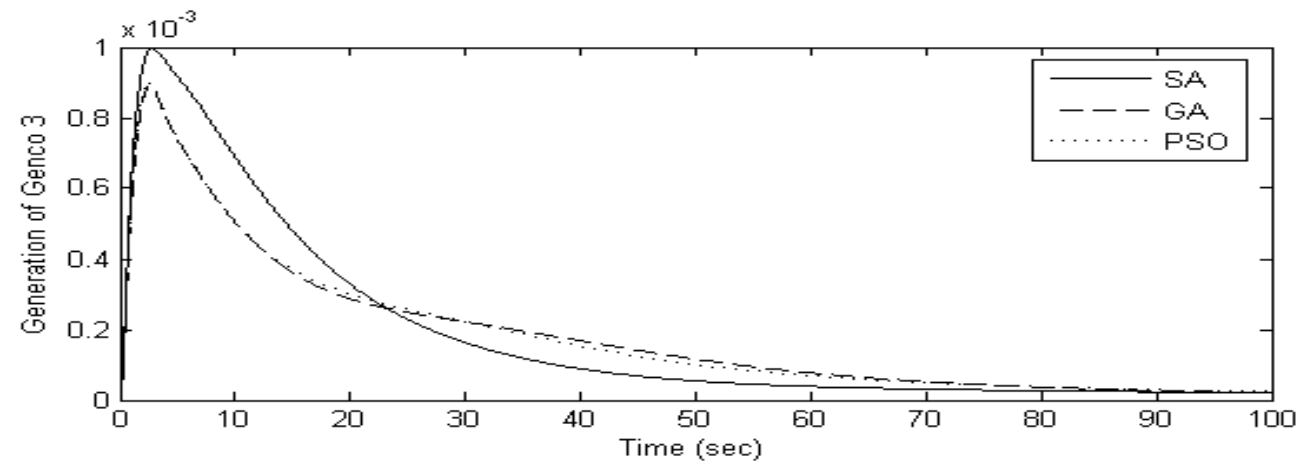

Fig 5: Generation of Gencos of Area I
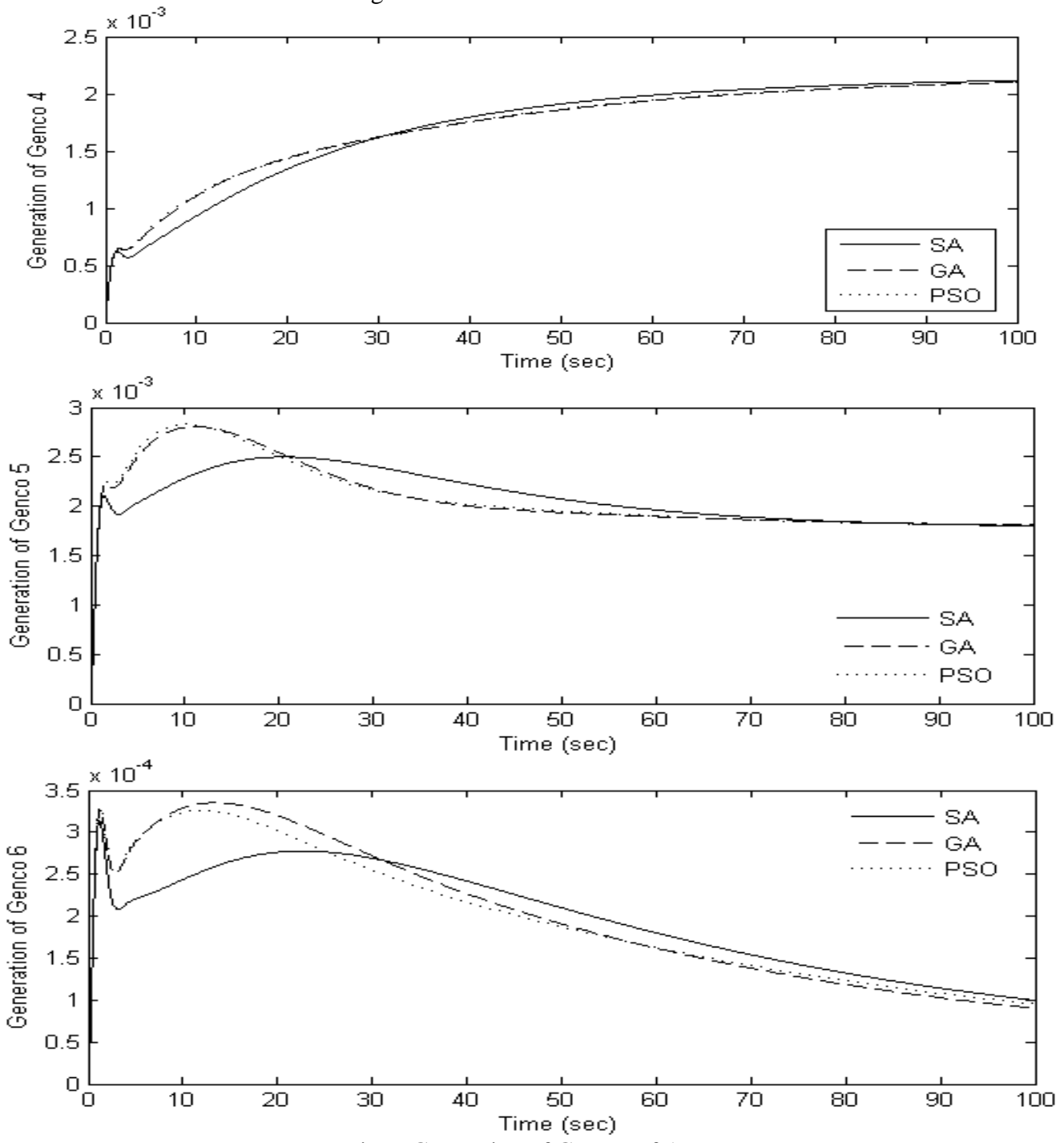

Fig 6: Generation of Gencos of Area II

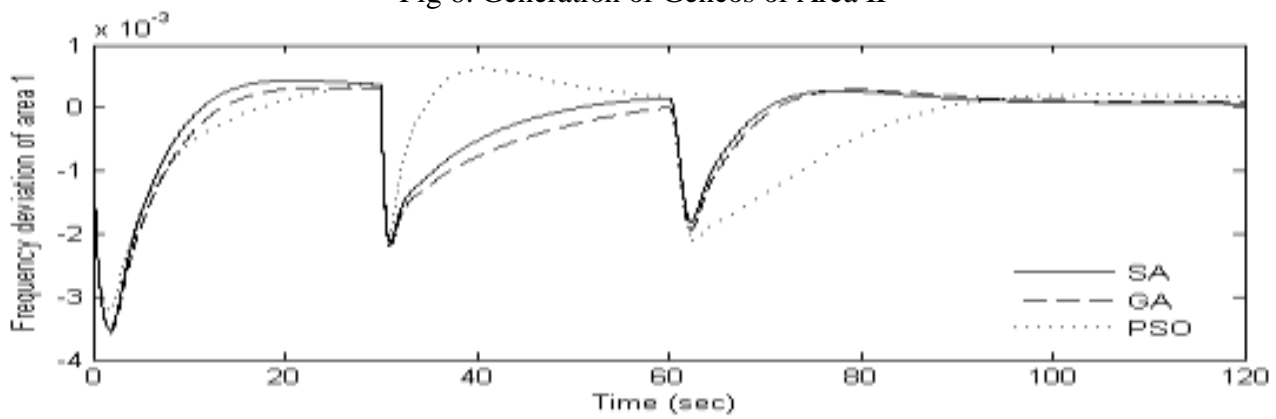



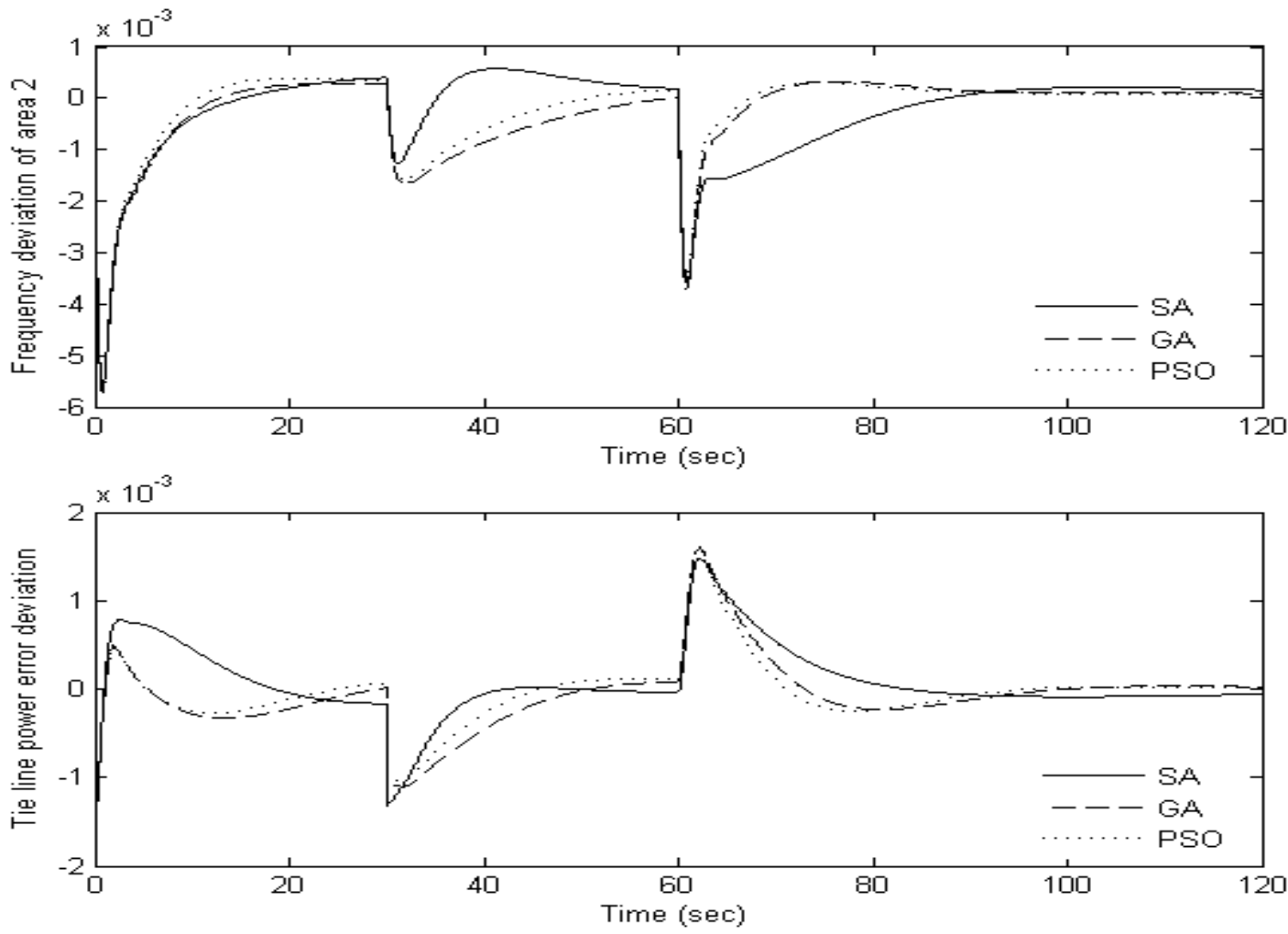

Fig 7: Comparison of Frequency deviations and tie line power error deviations during contract violation
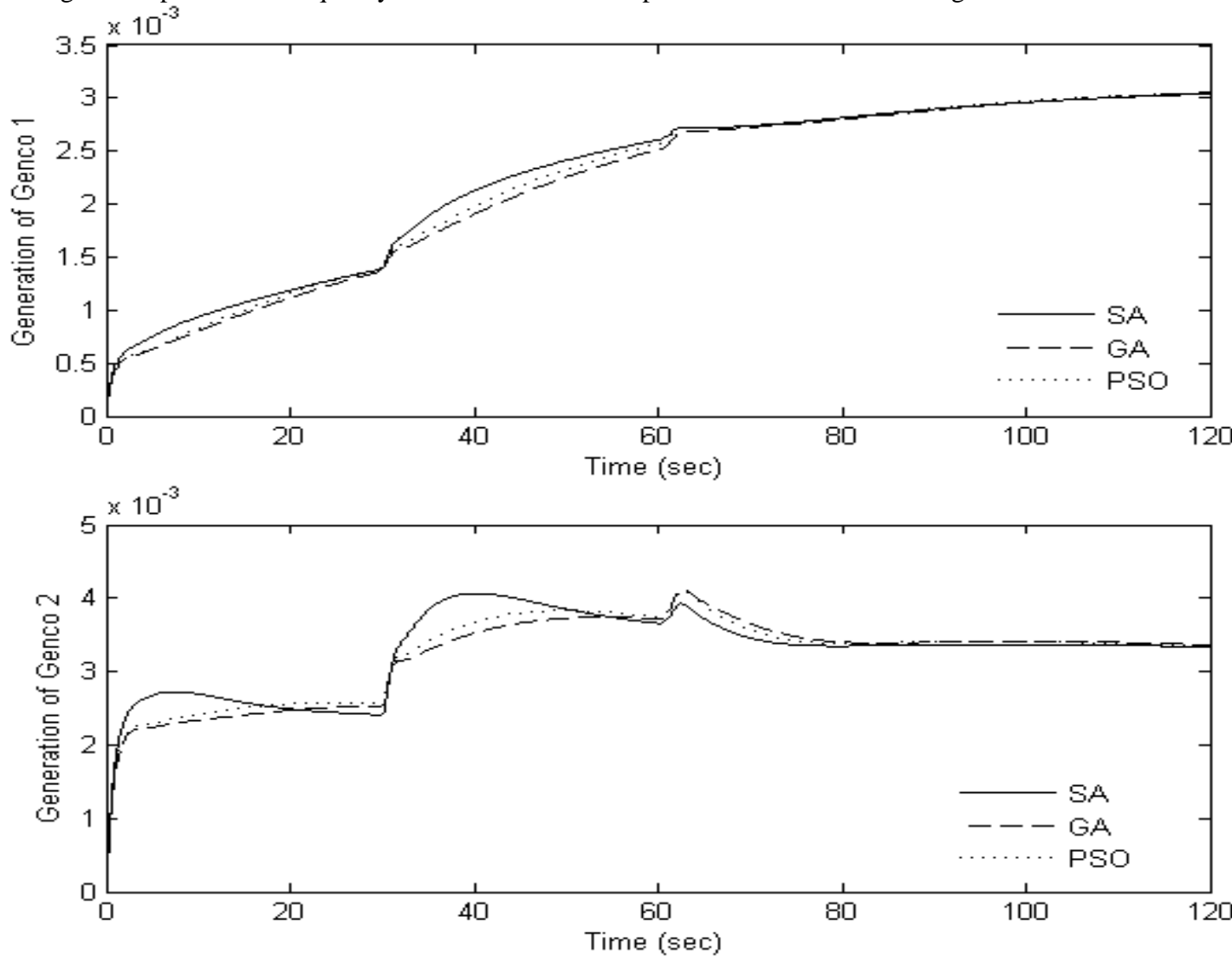

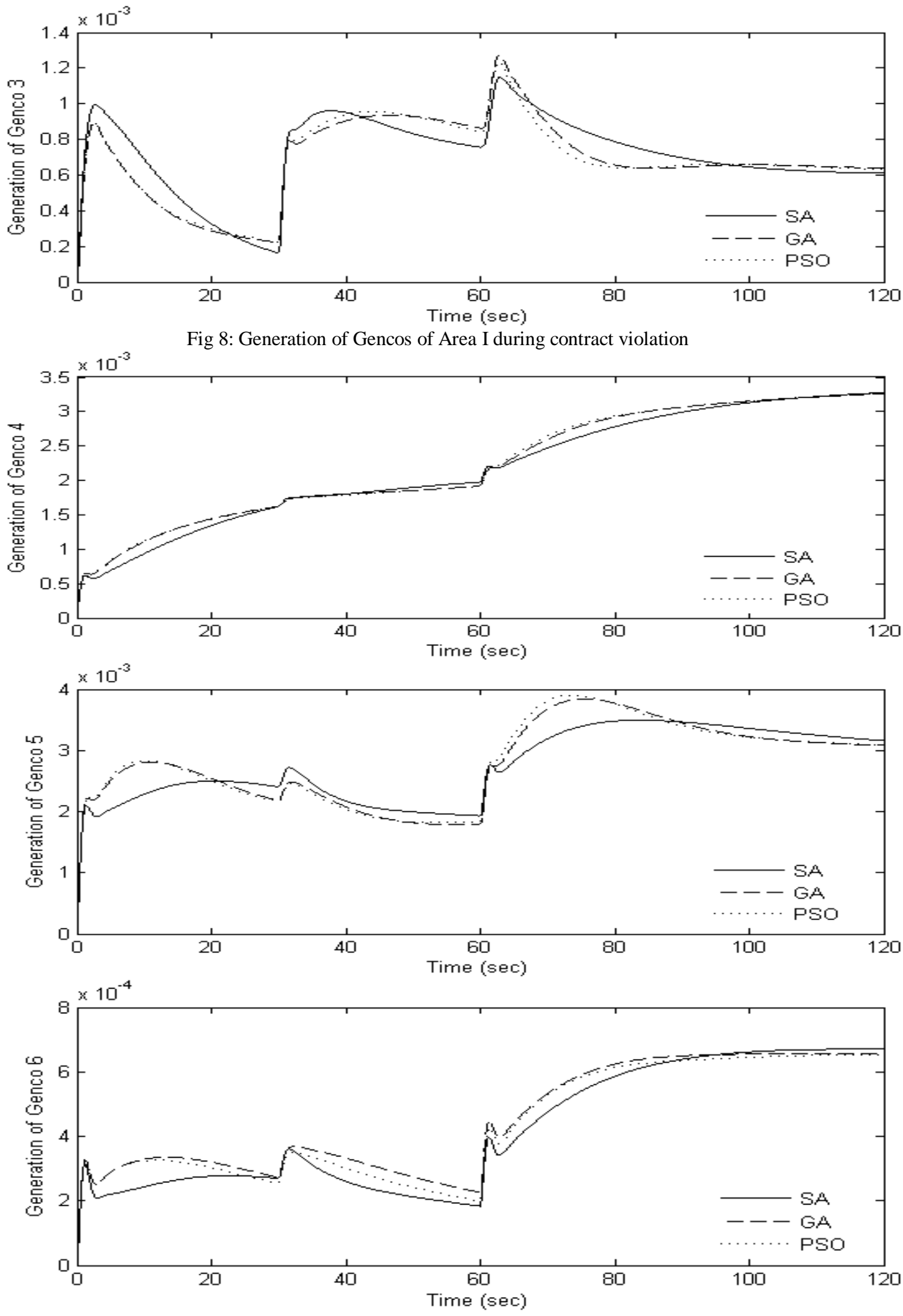

Fig 9: Generation of Gencos of Area II during contract violation 


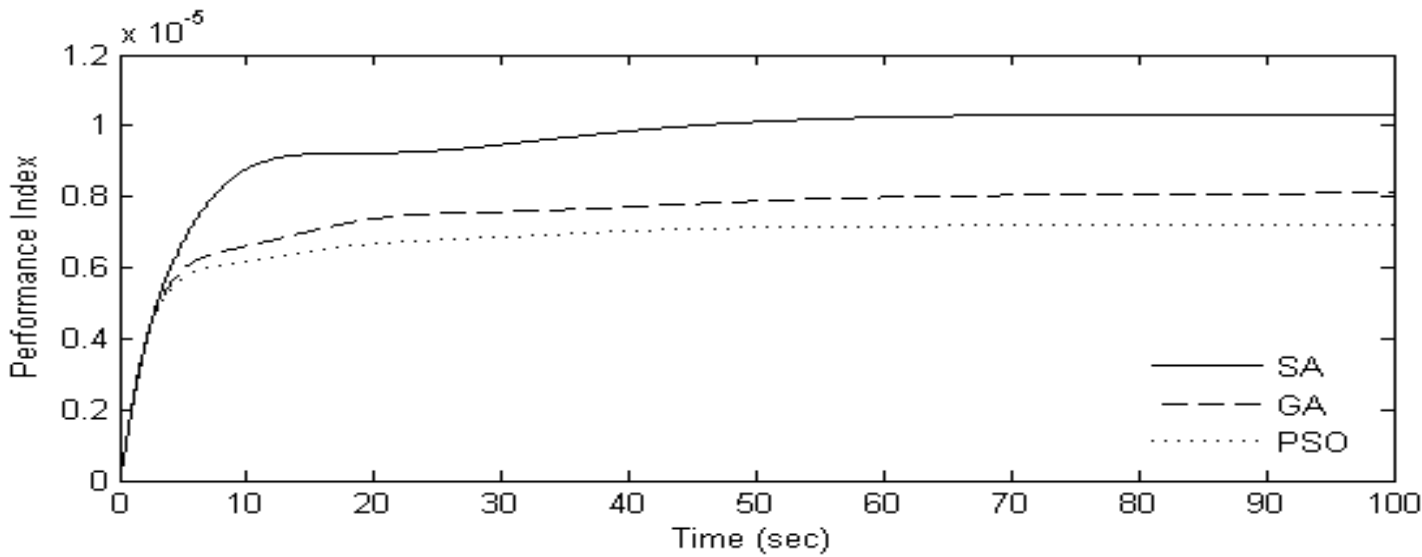

Fig 10: Comparison of performance index values during normal case

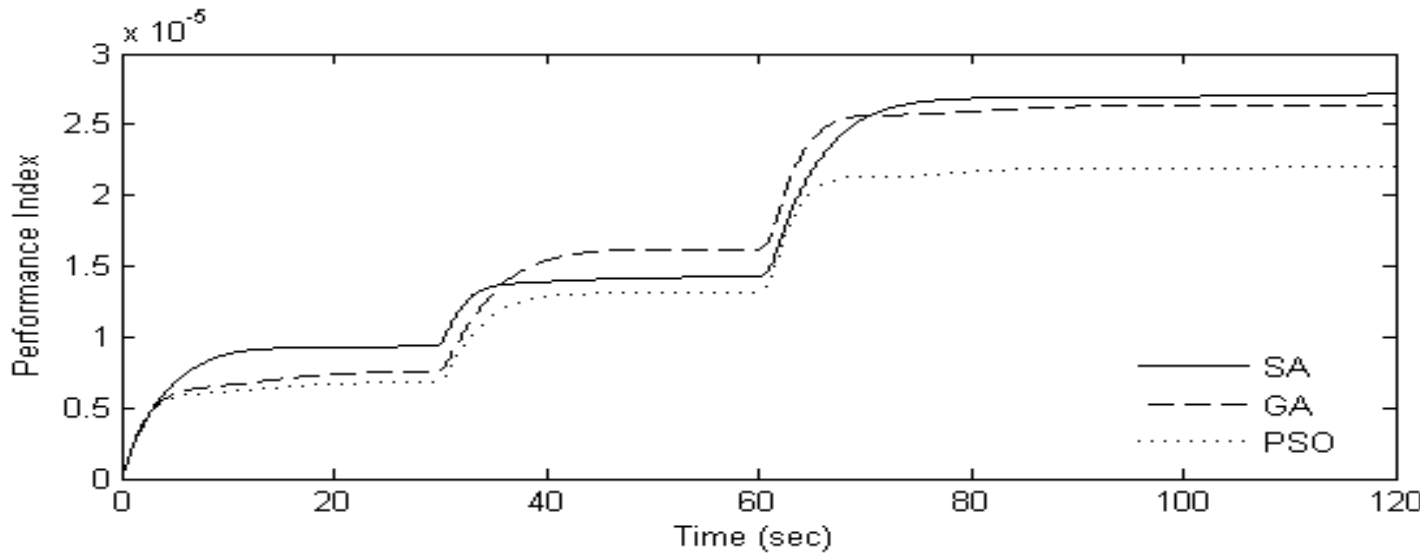

Fig 11: Comparison of performance index values during contract violation

\section{CONCLUSIONS}

Various evolutionary techniques have been successfully applied to design the value of integral controller of the system under deregulated scenario. The system employed to demonstrate these techniques is hydrothermal system under deregulated scenario. The technique of ISE criterion has been employed to determine the best technique in the design of integral controller. Out of all the techniques proposed, the PSO technique has demonstrated better results than the other techniques in terms of Peak time, overshoot and settling time. The performance index of the system with PSO is also very less which indicates the superior working of the system

\section{Appendix}

(a) System data

$T_{p 1}, T_{p 2}=20 \mathrm{~s} ; \quad K_{p 1}, K_{p 2}=120$ Hz/p.u.Mw; $P_{r 1}, P_{r 2}=1200 \mathrm{Mw} ; \quad T_{t}=0.3 \mathrm{~s} ; \quad T_{g}=0.08 \mathrm{~s}, \quad T_{w}=1 \mathrm{~s} ;$ $T_{r}=5 \mathrm{~s}, T_{1}=41.6 \mathrm{~s}, T_{2}=0.513 \mathrm{~s} ; R_{1}, R_{2}=2.4 \mathrm{~Hz} / \mathrm{pu} \mathrm{Mw} ; T_{12}=0.0866 \mathrm{~s} ; B_{1}, B_{2}=0.4249 \mathrm{p} . \mathrm{M} \mathrm{Mw} / \mathrm{Hz}$;

(b) CES data: $T_{1}=0.279 ; T_{2}=0.026 ; T_{3}=0.411 ; T_{4}=0.1 ; K_{C E S}=0.3 ; T_{C E S}=0.0352$

(c) SSSC data: $T_{1}=0.188 ; T_{2}=0.039 ; T_{3}=0.542 ; T_{4}=0.14 ; K_{S S S C}=0.292 ; T_{S S S C}=0.030$

\section{REFERENCES}

[1] C. Concordia and L.K.Kirchmayer, "Tie-Line Power and Frequency Control of Electric Power System - Part II", AIEE Transaction, April 1954, Vol. 73, Part- 111-A, pp. 133-146.

[2] M.L.Kothari, B.L.Kaul and J.Nanda, "Automatic Generation Control of Hydro-Thermal system" , journal of Institute of Engineers(India), Oct 1980, Vo1.61, pt EL2, , pp. 85-91.

[3] Chun-Feng Lu, Chun-Chang Liu and Chi-Jui Wu. "Effect of battery energy storage system on load frequency control considering governor dead band and generation rate constraints" IEEE transactions on energy conversions Vol. 10 September 1995, pp. 555561.

[4] Kushik HJ, Kramer KG, Domnik H " Battery energy storage - another option for load frequency control and instantaneous reserve" IEEE Trans Energy Conv 1986, 1(1), pp.46-51.

[5] Ise T, Mitani Y, Tsuji K, "Simultaneous active and reactive power control of superconducting magnetic energy storage to improve power system dynamic performance” IEEE Trans Energy Deliv 1986, 1, pp.143-150. 
[6] Tripathy SC, Balasubramanian R, Chandramohan Nair PS “ Effect of superconducting magnetic energy storage on automatic generation control considering governing deadband and boiler dynamics" IEEE Power Syst 1992, 7(3), pp. 1266-1273

[7] Tripathy SC, Juengst KP " Sampled data automatic generation control with superconducting magnetic energy storage in power systems" IEEE Trans Energy Conv 1997, 12(2), pp.187-191.

[8] Hingorani NG, Gyugyi L, "Understanding FACTS: concepts and technology of flexible AC transmission systems" New York, IEEE Press: 2000.

[9] Gyugyi L, Schauder CD, Sen KK "Static synchronous series compensator: a solid-state approach to the series compensation of transmission lines" IEEE Trans Energy Deliv 1997, 12(1), pp.406-417.

[10] Ngamroo I, Tippayachai J, Dechanupaprittha S "Robust decentralised frequency stabilisers design of Static synchronous series compensator by taking system uncertainties into consideration" Electrical power energy systems 2006, 28, pp. 513-524.

[11] Banerjee S, Chatterjee JK, Tripathy SC. "Application of magnetic energy storage unit as continuous var controller" IEEE Trans Energy Conver 1990, 5 (1), pp.39-45.

[12] Tripaty SC, , Kalantar M, Balasubramanian R "Dynamics and stability of wind and diesel turbine generators with superconducting magnetic energy storage unit on an isolated power system" IEEE Trans Energy Conver 1991;6 (4):579-85.

[13] Banerjee S, Chatterjee JK, Tripathy SC “Application of magnetic energy storage unit as load frequency stabiliser. IEEE Trans Energy Conver 1990, 5 (1),pp. 46-51.

[14] Jayath Kumar, Kah-Hoeng and Gerald Sheble, "AGC simulator for price based operation part- 1", IEEE Transactions on Power Systems, vol.12,no.2, May 1997,pp. 527-532.

[15] Jayant Kumar, Kah-Hoeng and Gerald Sheble, "AGC simulator for price based operation part- 2", IEEE Transactions on Power Systems, Vol.12, no. 2, May1997, pp 533-538

[16] Bjorn H. Bukken and Oves Grande "Automatic generation control in a deregulated environment" IEEE Transactions on Power Systems, vol. 13. No. 4 Nov 1998, pp. 1401-1406.

[17] V. Donde, M. A. Pai and I. A. Hiskens, "Simulation and optimization in an AGC system after deregulation", IEEE Trans. on Power systems, Vol. 16, No 3, Aug 2001, pp 481-489.

[18] "Dynamic Models for steam and Hydro Turbines in Power system studies," IEEE committee report. Transactions in Power Apparatus \&Systems Vol.92,No.6,Nov./Dec.1973,pp.1904-915.

[19] J. Nanda, Lalit Chandra Saikia, "Comparison of Performances of Several Types of Classical Controller in Automatic Generation Control for an Interconnected Multi-Area Thermal System", Proceedings of 2008 Australasian Universities Power Engineering Conference, Paper No 22.

[20] Dhanalakshmi, S. Kannan, S. Mahadevan, “ Market modes for deregulated environment - A review”, Proceedings of 2011 International conference on Emerging Trends in Electrical and Computer Technology (ICETECT), 23-24 March 2011.

[21] S. Kirkpatrick, C.D. Gelatt, and M.P.Vecchi, "Optimization by Simulated Annealing," Science Journal, May 1983,Vol. 220, NO. 4598, pp. 671-680.

[22] Rong-Ceng Leou, "A new method for unit maintenance scheduling considering reliability and operation expense," Electrical Power \& Energy Systems Journal Vol.28, 2006,pp.471-481.

[23] M.A.Abido,"Robust Design of Multimachine Power System Stabilizers Using Simulated Annealing “IEEE Trans. Energy Conversion. Vol.15 (3),2000, pp 297-304.

[24] E.Aarts and J. Korst, "Simulated Annealing and Boltzmann Machines: A Stochastic Approach to Combinatorial Optimization and Neural Computing," John Wiley \& Sons, 1989.

[25] Ghoshal SP, Goswami SK. "Application of GA based optimal integral gains in fuzzy based active power-frequency control of nonreheat and reheat thermal generating systems". Electr Power Syst Res 2003;67:79-88.

[26] Sinha Nidul, Lai Loi Lei, Rao Venu Gopal. "GA optimized PID controllers orautomatic generation control of two area reheat thermal systems under deregulated environment". In: IEEE international conference on electric utility deregulation, restructuring and power technologies, Nanjing, China, 6-9 April;2008.

[27] Praghnesh Bhatt, Ranjit Roy, S.P. Ghoshal. “GA/particle swarm intelligence based optimization of two specific varieties of controller devices applied to two-area multi-units automatic generation control”, Electrical Power \& Energy Systems Journal Vol.32, pp.299-310, 2010.

[28] Al-Awami, A.T. A particle-swarm based approach of power system stability enhancement with UPFC. Elec. Power and Energy Syst., (29): 251-259, 2007.

[29] Miranda, V. and N. Fonseca, 2002. New evolutionary particle swarm algorithm (EPSO) applied to voltage/VAR control. The 14th PSCC Conf. (PSCC'02-2002), Seville, Spain.

[30] Blackwell, T. and P.J. Bentley, 2002. Don't push me! Collision-avoiding swarms. IEEE Cong. On Evol. Comput., Honolulu, Hawaii USA.

[31] Krink, T., J.S. Vesterstrøm and J. Riget, 2002. PSO with spatial particle extension, Proc. of the 4th Congress on Evol. Comput., (CEC-2002). 